\title{
Anosmia but Not Ageusia as a COVID-19-Related Symptom among Cancer Patients-First Results from the PAPESCO-19 Cohort Study
}

\author{
Ke Zhou ${ }^{1, *}$, Audrey Blanc-Lapierre ${ }^{2}$, Valérie Seegers ${ }^{2}$, Michèle Boisdron-Celle ${ }^{3}$, Frédéric Bigot ${ }^{4}$, \\ Marianne Bourdon ${ }^{1,5}$, Hakim Mahammedi ${ }^{6}$, Aurélien Lambert ${ }^{7}{ }^{(0}$, Mario Campone ${ }^{8}$, Thierry Conroy ${ }^{7}{ }^{(1)}$, \\ Frédérique Penault-Llorca ${ }^{9}$, Martine M. Bellanger ${ }^{1,10}{ }^{(1)}$ and Jean-Luc Raoul ${ }^{8}{ }^{\circledR}$
}

Citation: Zhou, K.; Blanc-Lapierre, A.; Seegers, V.; Boisdron-Celle, M.; Bigot, F.; Bourdon, M.; Mahammedi, H.; Lambert, A.; Campone, M.; Conroy, T.; et al. Anosmia but Not Ageusia as a COVID-19-Related Symptom among Cancer Patients-First Results from the PAPESCO-19 Cohort Study. Cancers 2021, 13, 3389. https://doi.org/ 10.3390/cancers13143389

Academic Editor: Alexandar Tzankov

Received: 25 May 2021

Accepted: 29 June 2021

Published: 6 July 2021

Publisher's Note: MDPI stays neutral with regard to jurisdictional claims in published maps and institutional affiliations.

Copyright: (c) 2021 by the authors. Licensee MDPI, Basel, Switzerland. This article is an open access article distributed under the terms and conditions of the Creative Commons Attribution (CC BY) license (https:// creativecommons.org/licenses/by/ $4.0 /)$.
1 Department of Human and Social Sciences, Institut de Cancérologie de l'Ouest (ICO), 44805 Saint-Herblain, France; marianne.bourdon@ico.unicancer.fr (M.B.); martine.bellanger@ico.unicancer.fr (M.M.B.)

2 Department of Biostatistic, Institut de Cancérologie de l'Ouest, 44805 Saint-Herblain, France; audrey.blanc-lapierre@ico.unicancer.fr (A.B.-L.); valerie.seegers@ico.unicancer.fr (V.S.)

3 Department of Biopathology, Institut de Cancérologie de l'Ouest, 49055 Angers, France; michele.boisdron@ico.unicancer.fr

4 Department of Medical Oncology, Institut de Cancérologie de l'Ouest, 49055 Angers, France; frederic.bigot@ico.unicancer.fr

5 Research Unit UMR INSERM 1246 SPHERE, Universités de Nantes et Tours, 44035 Nantes, France

6 Department of Medical Oncology, Centre Jean Perrin, 63011 Clermont-Ferrand, France; hakim.mahammedi@clermont.unicancer.fr

7 Department of Medical Oncology, Institut de Cancérologie de Lorraine, 54511 Vandoeuvre-lès-Nancy, France; a.lambert@nancy.unicancer.fr (A.L.); t.conroy@nancy.unicancer.fr (T.C.)

8 Department of Medical Oncology, Institut de Cancérologie de l'Ouest, 44805 Saint-Herblain, France; mario.campone@ico.unicancer.fr (M.C.); jean-luc.raoul@ico.unicancer.fr (J.-L.R.)

9 Department of Biopathology and INSERM U1240, Centre Jean Perrin, 63011 Clermont-Ferrand, France; frederique.penault-1lorca@clermont.unicancer.fr

10 Department of Social Sciences, EHESP School of Public Health, 35043 Rennes, France

* Correspondence: ke.zhou@ico.unicancer.fr; Tel.: +33-2-40-67-99-00

Simple Summary: COVID-19 has some clinical manifestations that are similar to the side effects of cancer treatments such that cancer patients may fail to distinguish COVID-19 symptoms from those of their treatments. The PAPESCO-19 study investigated 13 COVID-19 symptoms and confirmed that in combination with anorexia, fever, headache, and rhinorrhea, anosmia has a strong association with COVID-19 for cancer patients while dysgeusia/ageusia does not.

Abstract: Background: Cancer patients may fail to distinguish COVID-19 symptoms such as anosmia, dysgeusia/ageusia, anorexia, headache, and fatigue, which are frequent after cancer treatments. We aimed to identify symptoms associated with COVID-19 and to assess the strength of their association in cancer and cancer-free populations. Methods: The multicenter cohort study PAPESCO-19 included 878 cancer patients and 940 healthcare workers (HCWs). At baseline and quarterly thereafter, they reported the presence or absence of 13 COVID-19 symptoms observed over 3 months and the results of routine screening RT-PCR, and they were systematically tested for SARS-CoV-2-specific antibodies. We identified the symptom combinations significantly associated with COVID-19. Results: Eight percent of cancer patients were COVID-19 positive, and 32\% were symptomatic. Among the HCWs, these proportions were 9.5 and 52\%, respectively. Anosmia, anorexia, fever, headache, and rhinorrhea together accurately discriminated (c-statistic $=0.7027$ ) COVID-19 cases from cancer patients. Anosmia, dysgeusia/ageusia, muscle pain, intense fatigue, headache, and chest pain better discriminated (c-statistic $=0.8830$ ) COVID-19 cases among the HCWs. Anosmia had the strongest association in both the cancer patients (OR = 7.48, 95\% CI: 2.96-18.89) and HCWs (OR = 5.71, 95\% CI: 2.21-14.75). Conclusions: COVID-19 symptoms and their diagnostic performance differ in the cancer patients and HCWs. Anosmia is associated with COVID-19 in cancer patients, while dysgeusia/ageusia is not. Cancer patients deserve tailored preventive measures due to their particular COVID-19 symptom pattern. 
Keywords: cancer; COVID-19; symptoms; healthcare workers; anosmia; dysgeusia; ageusia; France; serological test; RT-PCR

\section{Introduction}

Because of the worldwide spread of COVID-19, patients with cancer might be more susceptible to SARS-CoV-2 infection [1]. Those who have had hematological malignancy, lung or metastatic cancer or who have undergone surgery or immunotherapy are at an even higher risk of severe symptoms, admission to an intensive care unit, mechanical ventilation or death [2-5]. Clinical factors, such as advanced cancer stage and subtype, may be associated with poorer COVID-19 outcomes [1,2,5] alongside age, sex, and comorbidities [5-8]. As a result, cancer patients deserve particular attention when identifying the specific early symptoms of COVID-19 for further diagnosis.

The combination of specific symptoms, including fever and persistent cough and more surprisingly, anosmia (loss of smell) and dysgeusia/ageusia (distortion/loss of the sense of taste) make it possible to diagnose individuals with COVID-19 [9-17]. However, smell and taste alteration are also frequently observed in cancer patients during treatments [18-23]. U.K. clinicians have raised concerns about this overlap, recommending that oncology patients be carefully advised, and they have called for more evidence on the topic [24].

Studies reporting associations between seroprevalence and self-reported symptoms for healthcare workers (HCWs) found that fever, malaise, and fatigue were especially common alongside anosmia and ageusia $[25,26]$. However, little is known about HCWs from oncology departments and cancer centers despite the fact that they have been a under major strain during the pandemic $[27,28]$.

In France, only one cross-sectional study reported significantly more frequent anosmia and ageusia in seropositive cancer patients and HCWs than in seronegative ones. This was demonstrated by analyzing factors associated with the seroprevalence of SARS-CoV-2 after the first lockdown among two small populations of seropositive patients and HCWs from a single cancer center in Burgundy [27]. Therefore, more research is needed to investigate the predictive values of COVID-19-related symptom patterns in patients undergoing cancer treatments.

We are conducting a French study involving two cohorts of cancer patients and HCWs, who were systematically tested for SARS-CoV-2 infection during the ongoing pandemic as described below. This paper aims to identify symptoms which may predict COVID-19 in cancer patients and HCW populations. Our findings may help guide COVID-19 diagnostic, screening, and prevention strategies for cancer patients.

\section{Materials and Methods}

\subsection{Study Design and Setting}

We initiated a multicenter cohort study involving cancer patients and HCWs-PAtients et PErsonnels de Santé des Centres de Lutte Contre le Cancer pendant l'épidémie de COvid-19 (PAPESCO-19)-at comprehensive cancer centers in three different French regions: the Nantes and Angers sites of the ICO Cancer Center (Western France); the Lorraine Cancer Center in Nancy (Eastern France); and the Jean Perrin Cancer Center in Clermont-Ferrand (Central France) [29]. These regions are of interest as the 2020 COVID-19 epidemic had different local impacts [30]. The PAPESCO-19 study consists of four work packages, each with a different focus: serological and clinical, public health, economic, and psychological. We plan to include 3500 individuals.

We collected previous COVID-19 tests and symptoms reported by participants when they enrolled at baseline, as explained below in Section 2.3 Data collection. We then prospectively examined participants' COVID-19-related outcomes at quarterly intervals: 3 , 6,9 , and 12 months. 
Although the study has a broad scope and is ongoing, this analysis is based on the serological and clinical work package using data collected between the first participant's enrollment on 17 June 2020, and the date of the first four-month report on 30 November. This data allowed the effects of two epidemic waves to be captured.

\subsection{Participants}

We included patients aged $\geq 18$ years attending cancer centers as part of an ongoing active treatment (radiotherapy, surgery, immunotherapy or chemotherapy) or monitoring of treatment completed more than a year earlier. HCWs (nurses, clinicians, and other cancer center staff) enrolled voluntarily after being informed of the study via email and the cancer center intranet. Cancer patients and HCWs were recruited from each of the three regions. Although both cohorts within a site would have been exposed to the same spatio-temporal spread of COVID-19, they were not designed to be comparable as the two populations were not matched on the baseline characteristics of age, sex or comorbidities.

Participants were eligible irrespective of whether they had presented with symptoms since start of the COVID-19 outbreak. The inclusion period was one year with follow-up visits planned every three months. All participants signed an informed consent form, and the study is being conducted in accordance with the Declaration of Helsinki. The Ethics Committee (CPP-IDF VIII, Boulogne-Billancourt) approved our study number 20.04 .15 on 15 May 2020.

\subsection{Data Collection}

\subsubsection{Study Questionnaires}

At baseline and follow-up, all participants completed questionnaires on sociodemographic and lifestyle characteristics and on COVID-19-related history, including exposure to infected people, self-reported COVID-19 symptoms (detailed below), results of previous RT-PCR tests, and ambulatory care use. For cancer patients, baseline demographic data (age and sex), cancer history, and clinical details were recorded in electronic case report forms (eCRFs). For the HCWs, we collected demographic data (age and sex), job role, and occupation type (e.g., physician, nurse, assistant nurse, or pharmacist) as well as clinical data (self-reported body weight and height, comorbidities, and comedications) based on a questionnaire.

\subsubsection{Blood Samples, Serological Tests and Routine RT-PCR Reported}

We used the lateral flow immunoassay (LFIA) NG-Test ${ }^{\circledR}$ IgG-IgM COVID-19 (NG Biotech Laboratoires, Guipry-Messac, France): "[an] immune colloidal technique intended for the qualitative detection of IgG and IgM antibodies against the SARS-CoV-2 nucleoprotein in serum or plasma" [31]. Studies comparing the clinical performance of LFIA NG-Test ${ }^{\circledR}$ with one or more automated immunoassays-the enzyme-linked immunosorbent assays (ELISA IgG/IgA) is the gold standard-and SARS-CoV-2 chemiluminescence enzyme immunoassays (CLIA-IgG) found similar results. The performance of LFIA tests showed a sensitivity to SARS-CoV-2-specific IgG of about 100\% (95\% CI: 95.5-100.0\%) for the late disease stage (14 days after symptom onset. The specificity during the same late disease stage was $95.3 \%$ (95\% CI: 90.7-97.7\%) for SARS-CoV-2-specific IgG and IgM [31-34].

Serological tests were performed in the clinical biology department of each cancer center. At baseline, they were able to detect SARS-CoV-2-specific IgG antibodies after an infection during the first epidemic wave [35].

Participants also reported the results of routine RT-PCR tests completed independently of this study as a result of symptoms or possible contacts.

\subsubsection{Reported Symptoms}

At baseline, participants reported COVID-19-related symptoms from the beginning of the epidemic, including the first epidemic wave. During a follow-up, patients reported symptoms since the previous visit, which was before blood sampling was carried out. 
At each follow-up, the questionnaire included detailed, predefined symptoms (including onset and end dates), which the patient did not identify as being related to any treatment. The symptoms included were fever $>38^{\circ} \mathrm{C}$, headache, anosmia, dysgeusia/ageusia, rhinorrhea, unusual cough, shortness of breath, muscle pain, intense fatigue, anorexia, red eyes (conjunctivitis), digestive disorders (diarrhea, vomiting, and abdominal pain), and chest pain $[36,37]$. Symptoms were not graded (NCI-CTCAE) as part of the study, but the vast majority were assumed to be mild (grade 1 ) because the cancer patients were instructed to seek hospital care in the event of moderate or severe symptoms.

\subsection{COVID-19 Test Outcomes and Symptoms}

Participants with at least one SARS-CoV-2-positive serological test or RT-PCR test result during the study were considered to have a COVID-19 positive outcome (COVID+), while participants with consistently negative test results throughout the study were considered to be uninfected (COVID-).

Participants were considered to be symptomatic if they reported any of the 13 listed symptoms at any point, which was in accordance with the definition of a symptomatic patient in the Infectious Diseases Society of America (IDSA)'s guidelines: "[having] at least one of the most common symptoms compatible with COVID-19" [38]. This approach was used by many previous studies $[11,13,15,25]$. Participants who did not report any of the 13 symptoms were considered asymptomatic [28,38].

We then analyzed the association between positive COVID-19 test results and reported symptoms to assess the cancer patient cohort and HCW cohort independently.

\subsection{Statistical Analysis}

We estimated the proportions of participants with positive serological tests or positive self-reported RT-PCR tests with a 95\% confidence interval (CI). No statistical comparison was made between the two cohorts.

During univariate analysis, we estimated the proportion of participants who were symptomatic and used logistic regression to estimate the odds ratios (ORs) of the association between COVID-19 test outcomes and symptom presentation. We also estimated the sensitivity (Se), specificity (Sp), and OR for every symptom. All diagnostic performance indicators were reported with a $95 \%$ CI.

We further investigated the symptom pattern associated with a positive COVID-19 test in a multivariate model. Backward logistic regression was performed, starting with a full model that included the 13 symptoms with a variable entry and removal threshold of $p=0.20$. None of these variables included missing data. We used the Akaike information criterion (AIC) for model selection. The model was developed independently in the patient and HCW cohorts.

We reported the models' Se, Sp, and accuracy values. C-statistic was used to evaluate the models' performance and discrimination ability [39,40].

To validate the final models, we stratified each cohort by sex, median age, and cancer features (for the cancer patient cohort), and combined two or more pertinent strata to perform the logistic regression if there were insufficient covariate variations in one stratum. We drew 75 and $25 \%$ of the samples at random from the cancer patient and HCW cohorts, respectively. To account for differences in epidemic exposure among the cancer centers, we grouped Nantes and Angers cancer patients as one subpopulation, and the Nancy and Clermont-Ferrand cancer patients as another. The same analysis was done for the HCWs.

Of note, we reported any missing data in the descriptive tables and excluded this missing data when calculating percentages. No imputation was made since the missing data were not included as covariates in the regression analysis. The Ennov Clinical ${ }^{\circledR}$ system was used for data collection, and SAS ${ }^{\circledR} 8.3$ and STATA ${ }^{\circledR} 14.2$ were used for statistical analysis. 


\section{Results}

\subsection{Population Characteristics}

Total enrollment was 878 cancer patients and $940 \mathrm{HCWs}$. The median age was 62 years (18-91) for the cancer patients and 40 for the HCWs (19-66). Women represented more than two-thirds of the cancer patients $(69 \%)$ and three-quarters of the HCWs $(81 \%)$. Forty-one percent $(330 / 811)$ of the cancer patients and $13 \%(123 / 940)$ of the HCWs had at least one comorbidity. A public-facing role was observed in $42 \%(204 / 487)$ of the cancer patients and $81 \%(740 / 917)$ of the HCWs (Table 1 and Table S1).

Table 1. Characteristics of cancer patients.

\begin{tabular}{|c|c|}
\hline Characteristics & Cancer Patients N (\%) \\
\hline & $\mathrm{N}=878$ \\
\hline \multicolumn{2}{|l|}{ Sex } \\
\hline $\begin{array}{c}\text { Male } \\
\text { Female }\end{array}$ & $\begin{array}{l}275(31.3) \\
603(68.7)\end{array}$ \\
\hline $\begin{array}{c}\text { Age } \\
\text { Median (Range) } \\
18-49 \\
50-64 \\
65-74 \\
\geq 75\end{array}$ & $\begin{array}{l}62(18-91) \\
171(19.5) \\
334(38.0) \\
264(30.1) \\
109(12.4)\end{array}$ \\
\hline $\begin{array}{c}\text { BMI } \\
\text { Median (Range) } \\
\text { Obesity (BMI } \geq 30) \\
\text { missing data }\end{array}$ & $\begin{array}{c}25(17-43) \\
141(19.9) \\
170\end{array}$ \\
\hline $\begin{array}{c}\text { Tobacco smoking status } \\
\text { Non-smoker } \\
\text { Former smoker } \\
\text { Current smoker } \\
\text { missing data }\end{array}$ & $\begin{array}{c}299(47.8) \\
228(36.4) \\
99(15.8) \\
252\end{array}$ \\
\hline $\begin{array}{c}\text { Public-facing role }{ }^{1} \\
\text { No } \\
\text { Yes } \\
\text { missing data }\end{array}$ & $\begin{array}{l}283(58.1) \\
204(41.9) \\
\quad 391 \\
\end{array}$ \\
\hline $\begin{array}{c}\text { No. of Comorbidities }{ }^{2} \\
\geq 1 \\
\text { missing data }\end{array}$ & $\begin{array}{c}330(40.7) \\
67\end{array}$ \\
\hline $\begin{array}{c}\text { No. of Comedications }{ }^{3} \\
\geq 1 \\
\text { missing data }\end{array}$ & $\begin{array}{c}235(29.0) \\
68\end{array}$ \\
\hline $\begin{array}{l}\text { Centers of inclusion } \\
\text { Nantes } \\
\text { Angers } \\
\text { Clermont-Ferrand } \\
\text { Nancy }\end{array}$ & $\begin{array}{l}201(22.9) \\
238(27.1) \\
159(18.1) \\
280(31.9)\end{array}$ \\
\hline $\begin{array}{l}\text { Symptoms } \\
\text { Symptomatic } \\
\text { Asymptomatic }\end{array}$ & $\begin{array}{l}282(32.1) \\
596(67.9)\end{array}$ \\
\hline $\begin{array}{c}\text { COVID-19 tests } 5 \\
\text { Any positive test } \\
\text { Positive serological test } \\
\text { Positive RT-PCR test }\end{array}$ & $\begin{array}{l}70(8.0) \\
59(6.7) \\
26(3.0)\end{array}$ \\
\hline $\begin{array}{l}1 \text { Public-facing role: The question asked wa } \\
\text { included: hypertension, diabetes, chronic re } \\
\text { loss, autoimmune disease, surgery under } \\
\text { corticosteroids, Nonsteroidal anti-inflamma } \\
\text { ulatory drugs; }{ }^{4} \text { Symptomatic: having at le } \\
\text { symptoms; }{ }^{5} \text { Positive test results: Any posi }\end{array}$ & $\begin{array}{l}\text { contact with the public?"; }{ }^{2} \text { Comorbidities } \\
\text { idney failure, chronic heart failure, weight } \\
\text { ast } 12 \text { months; }{ }^{3} \text { Comedications included } \\
\text { hunosuppressive drugs, and immunomod- } \\
\text { m; Asymptomatic: having no COVID-19 } \\
\text { ollow-ups. }\end{array}$ \\
\hline
\end{tabular}


Ninety percent $(845 / 878)$ of cancer patients were undergoing cancer treatments of whom $(433 / 878=55.6 \%)$ had metastatic cancer. Almost half $(371 / 811=46 \%)$ had breast cancer, followed by uterine, endometrial, and cervical $(86 / 811=11 \%)$. Among male cancer patients, prostate cancer was the most prevalent type $(59 / 262=23 \%)$, followed by urological $(56 / 262=21 \%)$. Fifty-nine percent $(462 / 788)$ received chemotherapy as the last treatment before their inclusion in this study (Table 2).

Table 2. Cancer features of patients.

\begin{tabular}{|c|c|c|c|}
\hline Cancer Features & COVID- N (\%) & COVID+ N (\%) & Total N (\%) \\
\hline & $\mathrm{N}=808$ & $\mathrm{~N}=70$ & $\mathrm{~N}=878$ \\
\hline \multicolumn{4}{|l|}{ Location } \\
\hline Breast & $335(45)$ & $36(54.5)$ & $371(45.7)$ \\
\hline $\begin{array}{c}\text { Uterine. Endometrial. } \\
\text { Cervical }\end{array}$ & $81(10.9)$ & $5(7.6)$ & $86(10.6)$ \\
\hline Colorectal & $32(4.3)$ & $3(4.5)$ & $35(4.3)$ \\
\hline Gastrointestinal & $22(3)$ & $1(1.5)$ & $23(2.8)$ \\
\hline Prostate & $59(7.9)$ & $0(0)$ & $59(7.3)$ \\
\hline Urological & $62(8.3)$ & $6(9.1)$ & $68(8.4)$ \\
\hline Lung & $65(8.7)$ & $8(12.1)$ & $73(9)$ \\
\hline Miscellaneous $^{1}$ & 89 (11.9) & 7 (10.6) & $96(11.8)$ \\
\hline missing data & 63 & 4 & 67 \\
\hline \multicolumn{4}{|l|}{ Treatment status } \\
\hline $\begin{array}{c}\text { Undergoing } \\
\text { treatment }\end{array}$ & $782(96.8)$ & $63(90.0)$ & $845(96.2)$ \\
\hline Being monitored & $26(3.2)$ & $7(10.0)$ & $33(3.8)$ \\
\hline \multicolumn{4}{|l|}{ Stage } \\
\hline Localized & $196(27.3)$ & $19(31.7)$ & $215(27.6)$ \\
\hline Locally advanced & $122(17.0)$ & $9(15.0)$ & $131(16.8)$ \\
\hline Metastatic & $401(55.8)$ & $32(53.3)$ & $433(55.6)$ \\
\hline missing data & 89 & 10 & 99 \\
\hline \multicolumn{4}{|l|}{ ECOG PS } \\
\hline 0 & $263(41.9)$ & $21(38.2)$ & $284(41.6)$ \\
\hline 1 & $333(53.1)$ & $31(56.4)$ & $364(53.4)$ \\
\hline$\geq 2$ & $31(4.9)$ & $3(5.5)$ & $34(5)$ \\
\hline missing data & 181 & 15 & 196 \\
\hline \multicolumn{4}{|l|}{$\begin{array}{l}\text { Years since the first } \\
\text { cancer diagnosis }\end{array}$} \\
\hline$\geq 1$ year & 467 (62.9) & $44(66.7)$ & $511(63.2)$ \\
\hline missing data & 65 & 4 & 69 \\
\hline \multicolumn{4}{|l|}{$\begin{array}{l}\text { Last treatment before } \\
\text { inclusion }\end{array}$} \\
\hline Chemotherapy & $425(58.7)$ & $37(57.8)$ & $462(58.6)$ \\
\hline Immunotherapy & $113(15.6)$ & $10(15.6)$ & $123(15.6)$ \\
\hline Targeted therapy & $139(19.2)$ & $16(25.0)$ & 155 (19.7) \\
\hline Hormone therapy & $88(12.2)$ & $7(10.9)$ & $95(12.1)$ \\
\hline Radiotherapy & $41(5.7)$ & $2(3.1)$ & $43(5.5)$ \\
\hline Surgery & $22(3.0)$ & $4(6.3)$ & $26(3.3)$ \\
\hline Miscellaneous & $23(3.2)$ & $0(0)$ & $23(2.9)$ \\
\hline missing data & 67 & 6 & 73 \\
\hline
\end{tabular}

$\overline{{ }^{1} \text { Including the upper respiratory tract, brain, endocrine gland neoplasms, connective and soft-tissue neoplasms, }}$ skin, and unidentified cancers.

\subsection{COVID-19 Outcomes}

Seventy cancer patients (8\%, 95\% CI: 6-10\%) (Table 1$)$ and 89 HCWs $(9.5 \%, 95 \%$ CI: 8-12\%) tested positive for COVID-19 (Table S1). Systematic serological tests detected COVID-19 cases in 6.7\% (95\% CI: 5-9\%) of cancer patients (Table 1) and 7.8\% (95\% CI: 
$6 \%-10 \%$ ) of HCWs (Table S1). Of one in five participants (16.7\% of cancer patients and $23.5 \%$ of HCWs) were having routine RT-PCR screening; 3\% (95\% CI: $2-4 \%$ ) of cancer patients tested positive (Table 1) and 5\% (95\% CI: 4-7\%) of HCWs (Table S1).

There was a significantly higher proportion of COVID+ results among female cancer patients than male patients $(p=0.04)$, and among cancer patients being monitored than those undergoing treatment $(p=0.01)$. Furthermore, a significantly higher proportion of cancer patients with kidney failure tested positive for COVID-19 than did those without this condition (Table S2).

Eighteen cancer patients (2.1\%) and four HCWs (0.4\%) were hospitalized: one cancer patient was admitted to the intensive care unit, and another died as a result of COVID-19. Overall, 70 cancer patients had a COVID-19 infection, which was asymptomatic or mild in $74.3 \%$ of cases, moderate in $22.8 \%$, and life-threatening in $2.8 \%$ with a mortality rate of $1.4 \%$.

Among cancer patients, the highest proportion of COVID+ was observed in Nancy (9.3\%) and the lowest in Clermont-Ferrand (6.3\%) (Table S3), though no significant differences were observed between the centers $(p=0.27)$. Despite a distance of less than $100 \mathrm{~km}$ between the sites, the HCWs in Nantes had more than double the proportion of positive COVID-19 tests than those in Angers (11.7 vs. 5.0\% respectively, $p=0.01$ ) (Table S3).

\subsection{Single Symptoms}

A total of $282(282 / 878=32 \%)$ cancer patients and $485(485 / 940=52 \%)$ HCWs were symptomatic (Table 1). Among the COVID+ participants, 29 cancer patients $(29 / 70=41 \%)$ and 8 HCWs $(8 / 89=9 \%)$ were asymptomatic.

In cancer patients, we noted differences between centers in reported symptom prevalence, with $16.1 \%$ in Nancy (a badly affected Eastern region) and $46.3 \%$ in Nantes (a less-affected region, $p<0.001$ ). Among the HCWs, we observed that after the 30-40-year age range, reported symptom prevalence decreased with increasing age $(p=0.004)$. Symptoms in HCWs were less prevalent in Angers than in Nantes (44.6 and 54.7\%, respectively, $p=0.019)$ and overall differences among centers were significant $(p=0.018)$ (Table S3).

In a univariate analysis of the cancer patient cohort, all symptoms except headache and chest pain showed statistical significance against COVID-19 test outcomes (Figure 1a). All symptoms showed significance for the HCWs (Figure 1b).

Figure 2a shows the OR of the association between each symptom and a positive COVID-19 test. Among cancer patients, anosmia had the highest OR (12.69, 95\% CI: 6.02-26.76). However, dysgeusia/ageusia had a lower OR (4.93, 95\% CI: 2.53-9.62) than fever $(\mathrm{OR}=5.69,95 \%$ CI: 3.32-9.76) and anorexia ( $\mathrm{OR}=6.02,95 \%$ CI: 3.10-11.70). Among the HCWs, anosmia and dysgeusia/ageusia had similar ORs (46.25, 95\% CI: 25.79-82.93; $45.35,95 \%$ CI: $25.69-80.04$, respectively), which were the highest of all of the symptoms.

The Se and Sp of each symptom are presented in Figure $2 \mathrm{~b}$. Anosmia was the most specific symptom for cancer patients ( $\mathrm{Sp}=0.98,95 \% \mathrm{CI}$ : 0.97-0.99). Anosmia and dysgeusia/ageusia were the most specific symptoms for the HCWs (anosmia Sp $=0.97,95 \%$ CI: $0.96-0.98$; dysgeusia/ageusia $\mathrm{Sp}=0.97,95 \%$ CI: $0.95-0.98$ ). Rhinorrhea was the most sensitive symptom, though not very high, for the cancer patients ( $\mathrm{Se}=0.39,95 \% \mathrm{CI}: 0.27-0.51$ ), and headache was the most sensitive HCW symptom ( $\mathrm{Se}=0.78,95 \%$ CI: 0.67-0.86). 
(a)

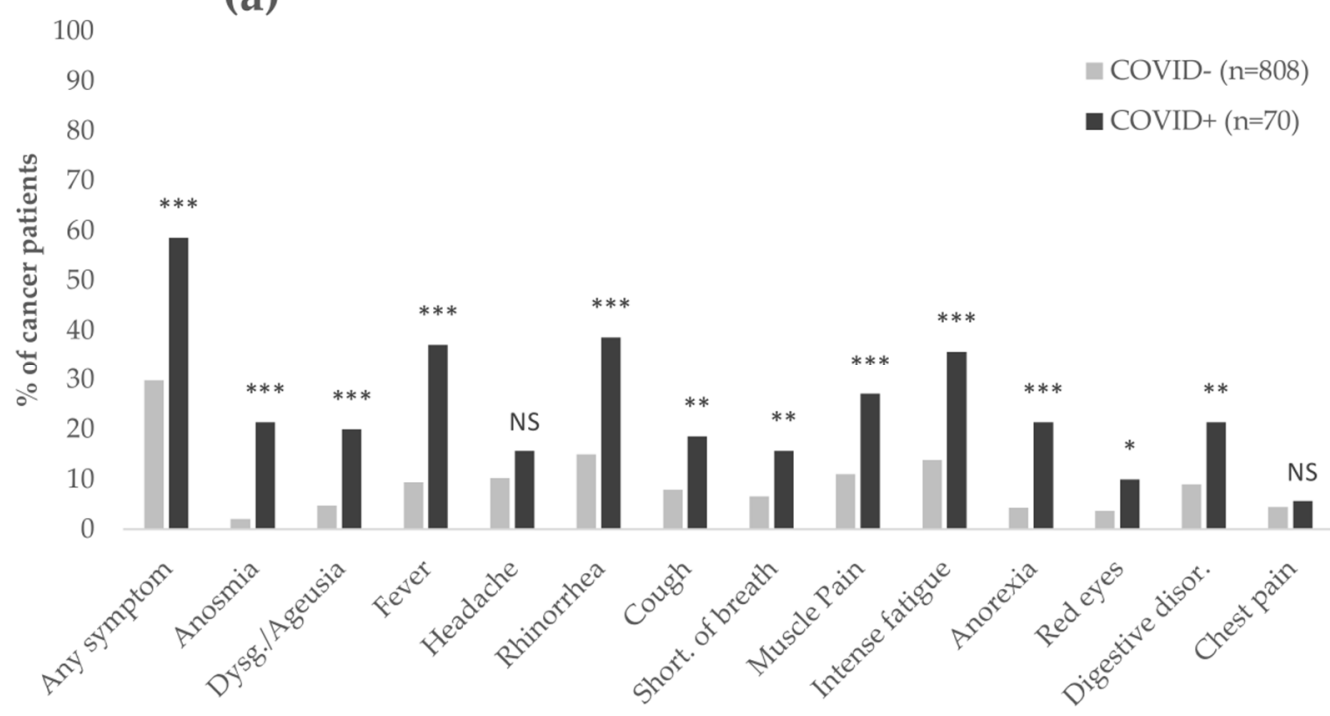

(b)

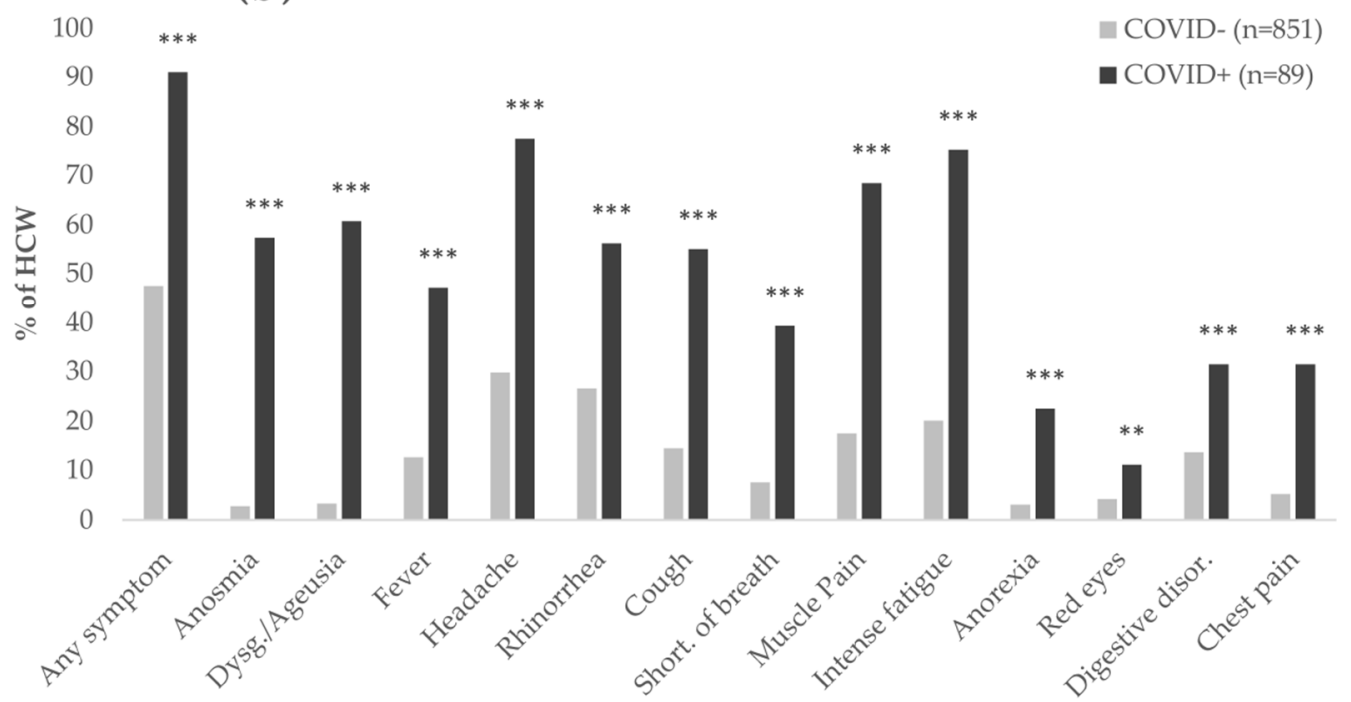

Figure 1. Bar chart, \% of COVID+ and COVID- participants reporting the presence of each symptom. (a) Symptoms in cancer patients. (b) Symptoms in healthcare workers. Any symptom: having at least one of the symptoms; Anosmia: smell blindness. In the questionnaire, the description was "loss of smell"; Dysg. (Dysgeusia): distortion of the sense of taste. Ageusia: loss of the sense of taste. In the questionnaire, the description was "alteration or even loss of taste"; Rhinorrhea: free discharge of a thin nasal mucus fluid, runny nose; Short. of breath: shortness of breath; Anorexia: Eating disorder; Digestive disor. (Digestive disorders): diarrhea, vomiting, and abdominal pain; $p$-value: univariate logistic regression, NS: Non-Significant, ${ }^{*} p<0.05,{ }^{* *} p<0.01,{ }^{* * *} p<0.001$. 


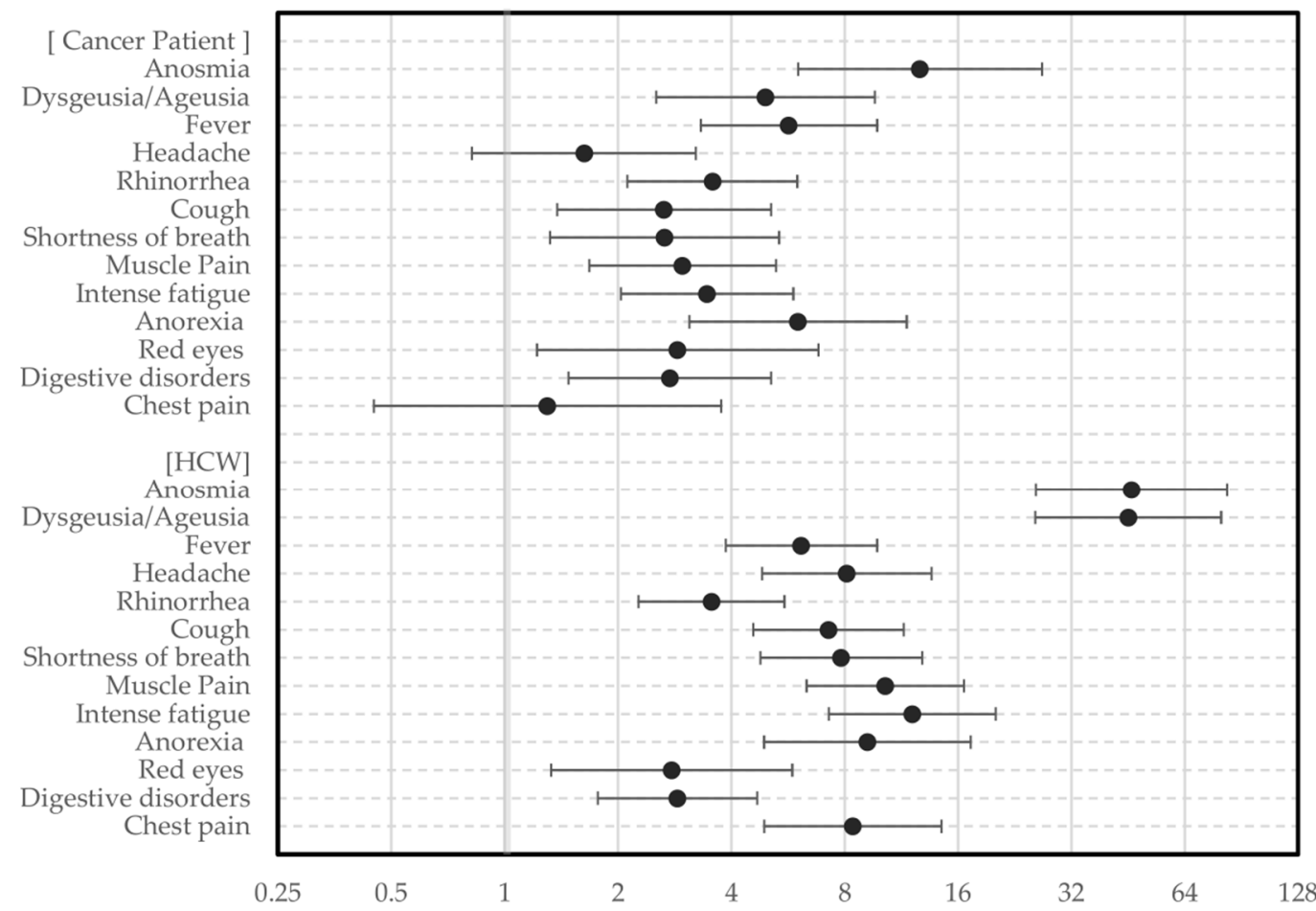

(a) Odds Ratios (95\% Confidence Interval)

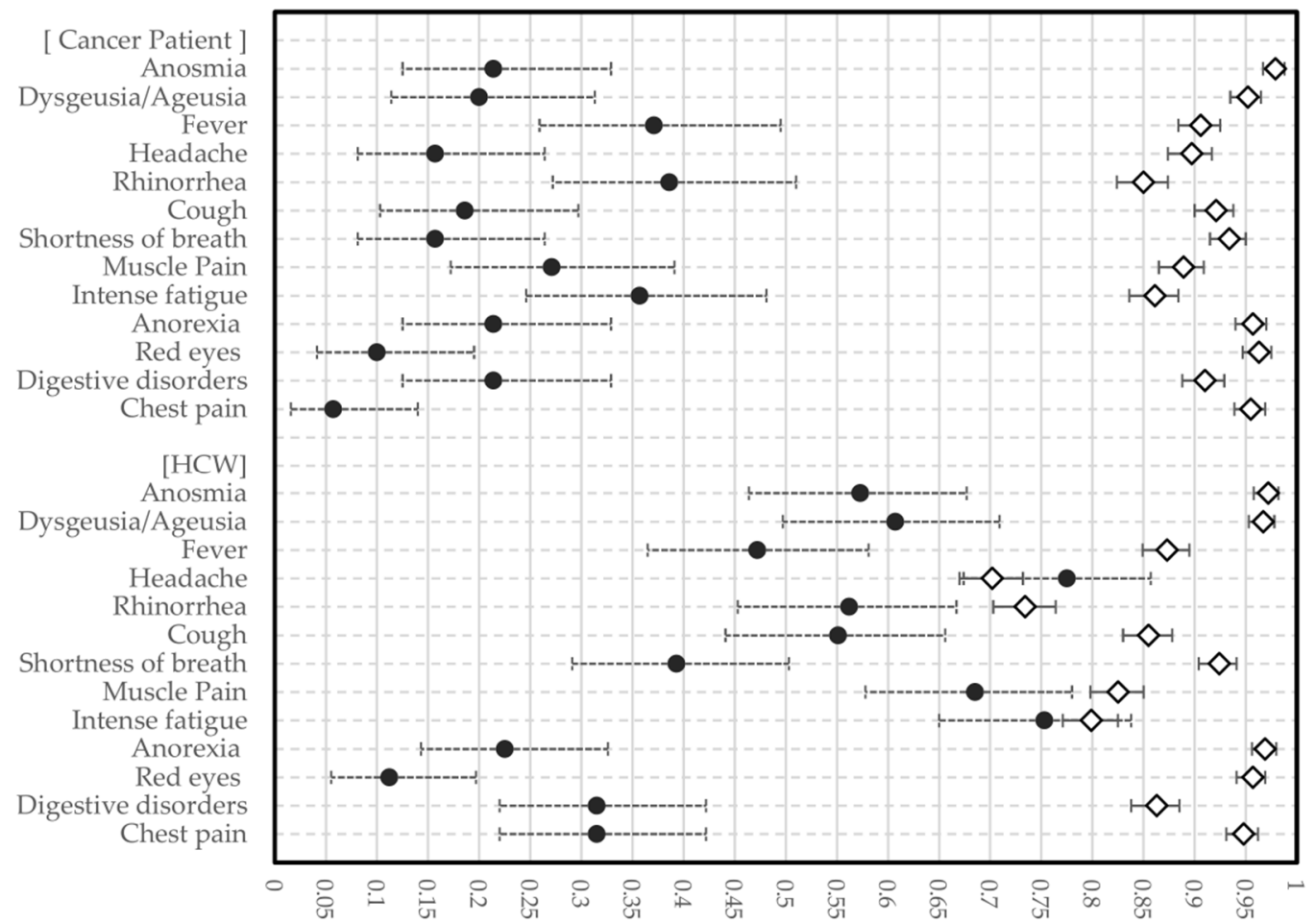

(b) Sensitivity (plot) and Specificity (rhombus)

Figure 2. Forest plot. (a) The Odds Ratio (OR) of the association between each symptom and a positive COVID-19 test. (b) Sensitivity (Se) and specificity (Sp) of each symptom.

\subsection{Combined Symptoms Predicting COVID-19}

Table 3 reports the results of the backward variable selection logistic regression. For cancer patients, in the final model anosmia was the most significant symptom $(\mathrm{OR}=7.48$, 
95\% CI: $2.96-18.89, p<0.001)$. Holding all other factors constant, a patient with anosmia has 7.5 times greater odds of having a positive test than a patient who did not report anosmia. Among the four other selected symptoms, anorexia, fever, and headache were the most significant $(p<0.05)$. Surprisingly, headache had an OR of less than 1 . It is worth noting that dysgeusia/ageusia had not been selected as a significant predictor of COVID-19 positive test outcome among cancer patients.

Table 3. Result of the backward logistic regression.

\begin{tabular}{|c|c|c|c|}
\hline Predictors & OR (95\% CI) & Wald & $p$-Value ${ }^{1}$ \\
\hline \multicolumn{4}{|c|}{ Cancer Patients' Full Model (N = 878) } \\
\hline Anosmia & $9.71(2.99-31.57)$ & 14.3 & $<0.001$ \\
\hline Dysgeusia/Ageusia & $0.77(0.26-2.35)$ & 0.21 & 0.651 \\
\hline Fever & $3.23(1.54-6.78)$ & 9.57 & 0.002 \\
\hline Headache & $0.33(0.12-0.90)$ & 4.75 & 0.029 \\
\hline Rhinorrhea & $1.98(0.95-4.10)$ & 3.36 & 0.067 \\
\hline Cough & $0.61(0.23-1.59)$ & 1.02 & 0.313 \\
\hline Shortness of breath & $1.34(0.48-3.72)$ & 0.32 & 0.575 \\
\hline Muscle pain & $1.15(0.50-2.67)$ & 0.11 & 0.738 \\
\hline Intense fatigue & $1.17(0.46-2.99)$ & 0.11 & 0.738 \\
\hline Anorexia & $4.52(1.69-12.09)$ & 9.03 & 0.003 \\
\hline Red eyes & $1.16(0.35-3.91)$ & 0.06 & 0.809 \\
\hline Digestive disorders & $0.65(0.25-1.66)$ & 0.82 & 0.366 \\
\hline Chest pain & $0.42(0.11-1.67)$ & 1.50 & 0.221 \\
\hline \multicolumn{4}{|c|}{ Cancer Patients' Final Model $(\mathrm{N}=878)$} \\
\hline Anosmia & $7.48(2.96-18.89)$ & 18.12 & $<0.001$ \\
\hline Anorexia & $3.82(1.66-8.76)$ & 9.99 & 0.002 \\
\hline Fever & $3.07(1.53-6.17)$ & 9.90 & 0.002 \\
\hline Headache & $0.30(0.12-0.76)$ & 6.49 & 0.011 \\
\hline Rhinorrhea & $1.81(0.93-3.51)$ & 3.08 & 0.079 \\
\hline \multicolumn{4}{|c|}{ Healthcare Workers' Full Model (N = 940) } \\
\hline Anosmia & $6.11(2.26-16.49)$ & 12.76 & $<0.001$ \\
\hline Dysgeusia/Ageusia & $5.30(1.96-14.34)$ & 10.78 & 0.001 \\
\hline Fever & $0.65(0.30-1.41)$ & 1.18 & 0.276 \\
\hline Headache & $2.08(0.96-4.48)$ & 3.47 & 0.062 \\
\hline Rhinorrhea & $0.67(0.33-1.34)$ & 1.29 & 0.256 \\
\hline Cough & $1.26(0.57-2.79)$ & 0.32 & 0.570 \\
\hline Shortness of breath & $0.90(0.37-2.20)$ & 0.05 & 0.825 \\
\hline Muscle pain & $2.01(0.91-4.41)$ & 3.01 & 0.083 \\
\hline Intense fatigue & $2.05(0.89-4.73)$ & 2.87 & 0.090 \\
\hline Anorexia & $1.25(0.47-3.30)$ & 0.20 & 0.654 \\
\hline Red eyes & $0.91(0.31-2.65)$ & 0.03 & 0.866 \\
\hline Digestive disorders & $0.78(0.38-1.60)$ & 0.47 & 0.494 \\
\hline Chest pain & $2.61(1.07-6.35)$ & 4.49 & 0.034 \\
\hline \multicolumn{4}{|c|}{ Healthcare Workers' Final Model $(\mathrm{N}=940)$} \\
\hline Anosmia & $5.71(2.21-14.75)$ & 12.93 & $<0.001$ \\
\hline Dysgeusia/Ageusia & $5.14(2.01-13.14)$ & 11.68 & 0.001 \\
\hline Muscle pain & $1.75(0.82-3.75)$ & 2.08 & 0.149 \\
\hline Intense fatigue & $1.78(0.85-3.72)$ & 2.34 & 0.126 \\
\hline Headache & $1.88(0.86-4.11)$ & 2.53 & 0.111 \\
\hline Chest pain & $2.42(1.11-5.27)$ & 4.95 & 0.026 \\
\hline
\end{tabular}

${ }^{1}$ Variable entry and removal threshold fixed at $p=0.20$.

For HCWs, anosmia and dysgeusia/ageusia were significant symptoms with the largest ORs for the COVID-19 positive test outcome (anosmia OR $=5.71,95 \%$ CI: 2.21-14.75; dysgeusia/ageusia OR $=5.14,95 \%$ CI: 2.01-13.14) in the final model. Muscle pain, intense fatigue, headache, and chest pain $(p<0.05)$ were also selected symptoms. 
Overall, the selected symptoms better classified COVID-19 test outcomes for HCWs than for cancer patients (c-statistic $=0.8830$ vs. 0.7027) (Table S4).

The equations used to estimate the probability of a COVID-19 positive test outcome are reported in Supplementary II.

\subsection{Model Validation}

In the cancer patient model, stratifying by sex, median age, and cancer-related variables did not influence the model's validity given the very limited change in the c-statistics (Table S4). The same was observed for cancer treatment types, such as chemotherapy and immunotherapy. Less than $10 \%$ variation in the c-statistics was observed within the 75 and $25 \%$ samples. Stratifying by centers of inclusion resulted in smaller variation in performance measurements (Table S4).

In the HCW model, the c-statistics ranged from 0.7989 to 0.9241 . The final model had relatively stable performance measurement values in all subpopulations (Table S4).

Finally, when comparing sub-datasets stratified with the same factors, the HCW model consistently performed better than the cancer patient model.

\section{Discussion}

Based on the PAPESCO-19 multicenter cohorts, the current study identified symptoms which could predict SARS-CoV-2 infection in 878 cancer patients and 940 oncology HCWs.

Proportions of COVID+ cases were similar; $8 \%$ for cancer patients and $9.5 \%$ for HCWs. Nevertheless, more cancer patients than HCWs had severe outcomes (hospitalized: 2.1 vs. $0.4 \%$; ICU and death: 1 vs. 0). Symptoms considered to be associated with COVID-19 had a lower prevalence among cancer patients (32\%) than among HCWs (52\%). Almost all COVID+ HCWs (91\%) were symptomatic, while approximately half (49\%) of COVID+ cancer patients reported symptoms. In contrast, $5 \%$ of asymptomatic cancer patients and $2 \%$ of asymptomatic HCWs were COVID+.

For the cancer patients, one immediate finding was that a single symptom had a weak relationship with COVID-19 test results. It is worth noting that cancer patients usually suffer from different symptoms, so they possibly failed to notice the additional symptoms of SARS-CoV-2 infection. Nevertheless, combining several symptoms (anosmia, fever, headache, rhinorrhea, and anorexia) discriminated COVID-19 positivity fairly well. This was consistently seen within different sub-datasets, stratified by factors such as cancer treatment or type. Negative association with headache may serve as a differential diagnosis criterion and improve diagnostic accuracy. When assessed in combination with the other symptoms, a headache more likely suggests a condition other than COVID-19, whereas its absence raises the possibility of having COVID-19. Cancer patients deserve tailored preventive measures irrespective of the absence of symptoms.

For the HCWs, single symptoms had a strong association with COVID-19 test results. We identified several common symptom combinations validated in previous studies. These were anosmia, dysgeusia/ageusia, muscle pain, and intense fatigue [11,15]. Our study further included headache and chest pain, which differed from other symptoms in the previous studies' models.

It is worth noting that, in PAPESCO-19, digestive symptoms, particularly diarrhea were not associated with COVID-19 positivity in contrast to other studies. However, in our population of cancer patients, diarrhea was reported in $21.4 \%$ of COVID+ cases and in $4 \%$ of COVID-; similarly for the HCWs, these figures were 31.5 and $13.7 \%$, respectively. These data were in accordance with what has been observed in the literature, with gastrointestinal incidence (mainly diarrhea) ranging from 4 to $50 \%$ of cases [27,41].

Anosmia, as a single symptom or when combined with others, remained strongly associated with COVID-19 positivity. While dysgeusia was also found to be a good predictor for identifying COVID-19 among the HCWs (though less frequent than anosmia [9-17]), this was not the case for the cancer patients. 
Our findings from the PAPESCO-19 study were strengthened by both the study period, which covered two main waves of the pandemic in France, and by the inclusion of different geographical locations having varying epidemic levels $[30,42]$. This diversity reinforced the robustness and extrapolability of our final models since symptom diagnostic performance depends on the prevalence of symptomatic and COVID+ cases. In addition, the design of our study enabled us to capture COVID-19 cases comprehensively with systematic testing of all participants irrespective of symptoms.

The overall COVID-19 prevalence we observed was, to a certain extent, comparable to a French survey that covered only the first wave, in which $7 \%$ of participants were COVID-19 positive [43]. There were significant regional differences in symptom prevalence and in the proportion of COVID+ cases among the HCWs, but not the cancer patients (Table S3). The effect of the cancer patients' self-protective measures should be investigated in future studies.

Severe COVID-19 cases might be underrepresented in our study. Only $1.2 \%$ of participants were hospitalized due to the infection and only one death was reported compared with 23 cancer-related deaths. It was more likely that individuals with SARS-CoV-2 infections had been admitted to specialized COVID-19 hospitals and did not attend cancer centers during the PAPESCO-19 recruitment period.

Self-reporting bias may have affected the collected data, especially the self-declared symptoms, which may have been overreported or underreported as was observed in previous studies [11,44]. In addition, recall bias was inevitable due to the gap between the participant's inclusion date (baseline questionnaire) and the first wave of the pandemic in France (mid-March 2020) [45].

Our estimates of COVID+ cases are partially based on the LFIA NG-Test ${ }^{\circledR}$, and we acknowledge that the reliability of COVID-19 serological tests is a function of the humoral immune response pattern. However, studies showed that antibody titres were negative in about $5 \%$ of symptomatic [46] and $15-40 \%$ of asymptomatic PCR-positive patients [47-49], so the LFIA tests received discordant technical evaluations $[47,50,51]$. They had a low sensitivity in acute settings and were not suitable as a stand-alone diagnostic for acutephase infection. However, they did identify additional COVID-19 cases among suspected patients [47].

The LFIA test was unable to detect early-stage infection [47] since antibodies take several days to reach detectable levels after contact with the virus [52]. Participants experiencing symptom onset earlier than 8-15 days before blood sampling might have had a false negative serological result [31-34,47]. However, this immunoassay is suitable for investigating individuals who present late after symptom onset and had a negative RT-PCR test (if a test were even available), assessing a population's past or recent seroprevalence of SARS-CoV-2 infection (e.g., mild if any COVID-19 symptoms) [53], and conducting epidemiologic studies after symptom onset [31,47]. Because of the longitudinal design of our study, an infected participant with a negative result at baseline (M0) was likely to have a positive result at the three-month follow-up (M3), a sufficient time interval that results in a quasi-perfect sensitivity (100\%, 95\% CI: $95.5-100.0 \%, 15$ days after symptom onset) of the serological test used in our study [31]. Because we considered participants with any positive result at $\mathrm{M} 0$ and $\mathrm{M} 3$ to be COVID+, they were recorded as COVID+ in our data.

The self-reported RT-PCR test was performed as part of a general screening practice, leading to a substantial number of under-detected cases [42]. Only one in five study participants was tested. Potential reasons for that small proportion may include the lack of testing resources during the first wave, the national health system's limited testing capacity, or the limited implementation of the test-trace-isolate strategy.

\section{Conclusions}

The combination of symptoms (e.g., anosmia, anorexia, fever, headache, and rhinorrhea) accurately identified cancer patients with COVID-19. Specifically, our results demonstrated that some symptoms, such as headache, dysgeusia, and ageusia, had completely 
different expression between cancer and cancer-free populations. Accurately predicting COVID-19 from identified symptoms in cancer patients would be helpful for the diagnosis, screening, and prevention of SARS-CoV-2 infection.

Supplementary Materials: The following are available online at https:/ / www.mdpi.com/article/ 10.3390/cancers13143389/s1, Supplementary I: Table S1. Characteristics of healthcare workers; Table S2. Cancer patient characteristics. COVID- versus COVID+; Table S3. Symptom prevalence and COVID-19 positive proportion by centers of inclusion; Table S4. Model validation; Supplementary II: Equations for calculating the estimated probability of a positive COVID-19 test outcome.

Author Contributions: Conceptualization, M.M.B., J.-L.R., M.B.-C., F.B., A.B.-L., V.S., M.B.; methodology, K.Z., M.M.B., A.B.-L., V.S.; validation, M.M.B., J.-L.R., A.B.-L., V.S.; formal analysis, K.Z.; investigation, F.B., H.M., A.L., M.C., T.C., F.P.-L.; writing-original draft, K.Z., M.M.B., J.-L.R.; writing-review and editing, all authors; visualization, K.Z.; supervision, M.M.B., M.C.; funding acquisition, M.C., M.M.B., J.-L.R., A.B.-L., V.S., M.B.-C. All authors have read and agreed to the published version of the manuscript.

Funding: The Nantes Metropolis financed partially the study (10\% of total budget). However, the PAPESCO-19 is an independent study and the ideas and opinions expressed in this work are those of the authors.

Institutional Review Board Statement: The study was conducted according to the guidelines of the Declaration of Helsinki. The study was approved by the Ethics Committee (Ref: CPP-IDF VIII, Boulogne-Billancourt) approved our study number 20.04.15 on 15 May 2020).

Informed Consent Statement: All participants provided signed informed consent to participate in the study.

Data Availability Statement: The data that support the findings of this study are available on request from the corresponding author (K.Z.).

Acknowledgments: We thank all staff from the study investigating centers and especially Valerie Pacteau, Marine Tigreat and Dahlia Bateta for their support in setting the study and the data collection and management. Our special thanks to Emma Tyson for her helpful comments.

Conflicts of Interest: The authors have no conflict of interest. The study was registered at ClinicalTrials. gov Identifier: NCT04421625.

\section{References}

1. $\quad$ Bakouny, Z.; Hawley, J.E.; Choueiri, T.K.; Peters, S.; Rini, B.I.; Warner, J.L.; Painter, C.A. COVID-19 and Cancer: Current Challenges and Perspectives. Cancer Cell 2020, 38, 629-646. [CrossRef]

2. Lee, L.Y.W.; Cazier, J.-B.; Starkey, T.; Briggs, S.E.W.; Arnold, R.; Bisht, V.; Booth, S.; Campton, N.A.; Cheng, V.W.T.; Collins, G.; et al COVID-19 prevalence and mortality in patients with cancer and the effect of primary tumour subtype and patient demographics: A prospective cohort study. Lancet Oncol. 2020, 21, 1309-1316. [CrossRef]

3. Dai, M.; Liu, D.; Liu, M.; Zhou, F.; Li, G.; Chen, Z.; Zhang, Z.; You, H.; Wu, M.; Zheng, Q.; et al. Patients with Cancer Appear more vulnerable to SARS-CoV-2: A Multicenter study during the COVID-19 outbreak. Cancer Discov. 2020, 10, 783-791. [CrossRef] [PubMed]

4. $\quad$ Berghoff, A.S.; Gansterer, M.; Bathke, A.C.; Trutschnig, W.; Hungerländer, P.; Berger, J.M.; Kreminger, J.; Starzer, A.M.; Strassl, R.; Schmidt, R.; et al. SARS-CoV-2 testing in patients with cancer treated at a tertiary care hospital during the COVID-19 pandemic. J. Clin. Oncol. 2020, 38, 3547-3554. [CrossRef] [PubMed]

5. Liu, Y.; Lu, H.; Wang, W.; Liu, Q.; Zhu, C. Clinical risk factors for mortality in patients with cancer and COVID-19: A systematic review and meta-analysis of recent observational studies. Null 2020, 1-13. [CrossRef] [PubMed]

6. Lee, L.Y.; Cazier, J.-B.; Angelis, V.; Arnold, R.; Bisht, V.; Campton, N.A.; Chackathayil, J.; Cheng, V.W.; Curley, H.M.; Fittall, M.W.; et al. COVID-19 mortality in patients with cancer on chemotherapy or other anticancer treatments: A prospective cohort study. Lancet 2020, 395, 1919-1926. [CrossRef]

7. Albiges, L.; Foulon, S.; Bayle, A.; Gachot, B.; Pommeret, F.; Willekens, C.; Stoclin, A.; Merad, M.; Griscelli, F.; Lacroix, L. Determinants of the outcomes of patients with cancer infected with SARS-CoV-2: Results from the gustave roussy cohort. Nat. Cancer 2020, 1, 965-975. [CrossRef]

8. Lièvre, A.; Turpin, A.; Ray-Coquard, I.; Le Malicot, K.; Thariat, J.; Ahle, G.; Neuzillet, C.; Paoletti, X.; Bouché, O.; Aldabbagh, K.; et al. Risk factors for coronavirus disease 2019 (COVID-19) severity and mortality among solid cancer patients and impact of the disease on anticancer treatment: A French nationwide cohort study (GCO-002 CACOVID-19). Eur. J. Cancer 2020, 141 , 62-81. [CrossRef] 
9. Bénézit, F.; Le Turnier, P.; Declerck, C.; Paillé, C.; Revest, M.; Dubée, V.; Tattevin, P.; Arvieux, C.; Baldeyrou, M.; Chapplain, J.-M. Utility of hyposmia and hypogeusia for the diagnosis of COVID-19. Lancet Infect. Dis. 2020. [CrossRef]

10. Iravani, B.; Arshamian, A.; Ravia, A.; Mishor, E.; Snitz, K.; Shushan, S.; Roth, Y.; Perl, O.; Honigstein, D.; Weissgross, R. Relationship between odor intensity estimates and COVID-19 prevalence prediction in a Swedish population. Chem. Senses 2020. [CrossRef]

11. Menni, C.; Valdes, A.M.; Freidin, M.B.; Sudre, C.H.; Nguyen, L.H.; Drew, D.A.; Ganesh, S.; Varsavsky, T.; Cardoso, M.J.; El-Sayed Moustafa, J.S.; et al. Real-time tracking of self-reported symptoms to predict potential COVID-19. Nat. Med. 2020, 26, 1037-1040. [CrossRef]

12. Lechien, J.R.; Chiesa-Estomba, C.M.; De Siati, D.R.; Horoi, M.; Le Bon, S.D.; Rodriguez, A.; Dequanter, D.; Blecic, S.; El Afia, F.; Distinguin, L. Olfactory and gustatory dysfunctions as a clinical presentation of mild-to-moderate forms of the Coronavirus Disease (COVID-19): A multicenter european study. Eur. Arch. Oto Rhino Laryngol. 2020, 1-11. [CrossRef]

13. Petersen, I.; Phillips, A. Three quarters of people with SARS-CoV-2 infection are asymptomatic: Analysis of English household survey data. Clin. Epidemiol. 2020, 12, 1039. [CrossRef] [PubMed]

14. Pierron, D.; Pereda-Loth, V.; Mantel, M.; Moranges, M.; Bignon, E.; Alva, O.; Kabous, J.; Heiske, M.; Pacalon, J.; David, R.; et al. Smell and taste changes are early indicators of the COVID-19 pandemic and political decision effectiveness. Nat. Commun. 2020, 11, 5152. [CrossRef] [PubMed]

15. Roland, L.T.; Gurrola, J.G.; Loftus, P.A.; Cheung, S.W.; Chang, J.L. Smell and taste symptom-based predictive model for COVID-19 diagnosis. Int. Forum Allergy Rhinol. 2020, 10, 832-838. [CrossRef] [PubMed]

16. Walker, A.; Pottinger, G.; Scott, A.; Hopkins, C. Anosmia and loss of smell in the era of Covid-19. BMJ 2020, 370. [CrossRef]

17. Carrillo-Larco, R.M.; Altez-Fernandez, C. Anosmia and Dysgeusia in COVID-19: A systematic review. Wellcome Open Res. 2020, 5. [CrossRef] [PubMed]

18. Steinbach, S.; Hummel, T.; Böhner, C.; Berktold, S.; Hundt, W.; Kriner, M.; Heinrich, P.; Sommer, H.; Hanusch, C.; Prechtl, A.; et al. Qualitative and quantitative assessment of taste and smell changes in patients undergoing chemotherapy for breast cancer or gynecologic malignancies. JCO 2009, 27, 1899-1905. [CrossRef] [PubMed]

19. De Vries, Y.C.; Boesveldt, S.; Kelfkens, C.S.; Posthuma, E.E.; van den Berg, M.M.G.A.; de Kruif, J.T.C.M.; Haringhuizen, A.; Sommeijer, D.W.; Buist, N.; Grosfeld, S.; et al. Taste and smell perception and quality of life during and after systemic therapy for breast cancer. Breast Cancer Res. Treat. 2018, 170, 27-34. [CrossRef]

20. McGreevy, J.; Orrevall, Y.; Belqaid, K.; Wismer, W.; Tishelman, C.; Bernhardson, B.-M. Characteristics of taste and smell alterations reported by patients after starting treatment for lung cancer. Support. Care Cancer 2014, 22, 2635-2644. [CrossRef]

21. Hong, J.; Omur-Ozbek, P.; Stanek, B.; Dietrich, A.; Duncan, S.; Lee, Y.; Lesser, G. Taste and odor abnormalities in cancer patients. J. Support Oncol. 2009, 7, 58-65. [PubMed]

22. Gamper, E.-M.; Zabernigg, A.; Wintner, L.M.; Giesinger, J.M.; Oberguggenberger, A.; Kemmler, G.; Sperner-Unterweger, B.; Holzner, B. Coming to your senses: Detecting taste and smell alterations in chemotherapy patients. A systematic review. J. Pain Symptom. Manag. 2012, 44, 880-895. [CrossRef] [PubMed]

23. Álvarez-Camacho, M.; Gonella, S.; Campbell, S.; Scrimger, R.A.; Wismer, W.V. A systematic review of smell alterations after radiotherapy for head and neck cancer. Cancer Treat. Rev. 2017, 54, 110-121. [CrossRef]

24. Russell, B.; Moss, C.; Rigg, A.; Hopkins, C.; Papa, S.; Van Hemelrijck, M. Anosmia and Ageusia are emerging as symptoms in patients with COVID-19: What does the current evidence say? Ecancermedicalscience 2020, 14. [CrossRef] [PubMed]

25. Nguyen, L.H.; Drew, D.A.; Graham, M.S.; Joshi, A.D.; Guo, C.-G.; Ma, W.; Mehta, R.S.; Warner, E.T.; Sikavi, D.R.; Lo, C.-H.; et al. Risk of COVID-19 among front-line health-care workers and the general community: A prospective cohort study. Lancet Publ. Health 2020, 5, e475-e483. [CrossRef]

26. Rudberg, A.-S.; Havervall, S.; Månberg, A.; Falk, A.J.; Aguilera, K.; Ng, H.; Gabrielsson, L.; Salomonsson, A.-C.; Hanke, L.; Murrell, B. SARS-CoV-2 Exposure, Symptoms and Seroprevalence in Healthcare Workers in Sweden. Nat. Commun. 2020, 11, 1-8. [CrossRef] [PubMed]

27. Ladoire, S.; Goussot, V.; Redersdorff, E.; Cueff, A.; Ballot, E.; Truntzer, C.; Ayati, S.; Bengrine-Lefevre, L.; Bremaud, N.; Coudert, B.; et al. Seroprevalence of SARS-CoV-2 among the staff and patients of a french cancer centre after first lockdown: The CanSEROcov Study. Eur. J. Cancer 2021, 148, 359-370. [CrossRef] [PubMed]

28. Favara, D.M.; McAdam, K.; Cooke, A.; Bordessa-Kelly, A.; Budriunaite, I.; Bossingham, S.; Houghton, S.; Doffinger, R.; Ainsworth, N.; Corrie, P.G. SARS-CoV-2 infection and antibody seroprevalence among UK Healthcare professionals working with cancer patients during the first wave of the COVID-19 pandemic. Clin. Oncol. R Coll. Radiol. 2021. [CrossRef]

29. Institut Cancerologie de l'Ouest. Patients and Health Staff of Cancer Centres During the Covid-19 Pandemic: Constitution of a Biological Collection Linked to a Prospective, Multicenter Cohort Study; US National Library of Medicine: Bethsedan, MD, USA, 2020.

30. Cauchemez, S.; Kiem, C.T.; Paireau, J.; Rolland, P.; Fontanet, A. lockdown impact on COVID-19 epidemics in regions across metropolitan France. Lancet 2020, 396, 1068-1069. [CrossRef]

31. Nicol, T.; Lefeuvre, C.; Serri, O.; Pivert, A.; Joubaud, F.; Dubée, V.; Kouatchet, A.; Ducancelle, A.; Lunel-Fabiani, F.; Le GuillouGuillemette, H. Assessment of SARS-CoV-2 serological tests for the diagnosis of COVID-19 through the evaluation of three immunoassays: Two Automated immunoassays (euroimmun and abbott) and one rapid lateral flow immunoassay (NG Biotech). J. Clin. Virol. 2020, 129, 104511. [CrossRef] 
32. Sweeney, N.; Merrick, B.; Galão, R.P.; Pickering, S.; Botgros, A.; Wilson, H.D.; Signell, A.W.; Betancor, G.; Tan, M.K.I.; Ramble, J.; et al. Clinical utility of targeted SARS-CoV-2 serology testing to aid the diagnosis and management of suspected missed, late or post-COVID-19 infection syndromes: Results from a pilot service implemented during the first pandemic wave. PLoS ONE 2021, 16, e0249791. [CrossRef]

33. Ghaffari, A.; Meurant, R.; Ardakani, A. COVID-19 serological tests: How well do they actually perform? Diagnostics 2020, 10, 453. [CrossRef] [PubMed]

34. Pickering, S.; Betancor, G.; Galão, R.P.; Merrick, B.; Signell, A.W.; Wilson, H.D.; Ik, M.T.K.; Seow, J.; Graham, C.; Acors, S.; et al. Comparative assessment of multiple COVID-19 serological technologies supports continued evaluation of point-of-care lateral flow assays in hospital and community healthcare settings. PLoS Pathog. 2020, 16, e1008817. [CrossRef]

35. Marklund, E.; Leach, S.; Axelsson, H.; Nyström, K.; Norder, H.; Bemark, M.; Angeletti, D.; Lundgren, A.; Nilsson, S.; Andersson, L.-M.; et al. Serum-IgG Responses to SARS-CoV-2 after mild and severe COVID-19 infection and analysis of IgG non-responders. PLoS ONE 2020, 15. [CrossRef] [PubMed]

36. WHO. Coronavirus-Symptoms. Available online: https://www.who.int/westernpacific/health-topics/coronavirus (accessed on 15 January 2021).

37. French Ministry of Health (Ministère des Solidarités et de la Santé). Les Réponses à Vos Questions Sur la COVID-19. Available online: https://solidarites-sante.gouv.fr/soins-et-maladies/maladies/maladies-infectieuses/coronavirus/tout-savoir-sur-lacovid-19/article/les-reponses-a-vos-questions-sur-la-covid-19 (accessed on 15 January 2021).

38. Hanson, K.E.; Caliendo, A.M.; Arias, C.A.; Hayden, M.K.; Englund, J.A.; Lee, M.J.; Loeb, M.; Patel, R.; El Alayli, A.; Altayar, O.; et al. The infectious diseases society of america guidelines on the diagnosis of COVID-19: Molecular diagnostic testing. Clin. Infect. Dis. 2021. [CrossRef]

39. Hosmer, D.W., Jr.; Lemeshow, S.; Sturdivant, R.X. Applied Logistic Regression; John Wiley \& Sons: Hoboken, NJ, USA, 2013; Volume 398, ISBN 0-470-58247-2.

40. Louviere, J.J.; Hensher, D.A.; Swait, J.D. Stated Choice Methods: Analysis and Applications; Cambridge University Press: Cambridge, UK, 2000; ISBN 0-521-78830-7.

41. Basse, C.; Diakite, S.; Servois, V.; Frelaut, M.; Noret, A.; Bellesoeur, A.; Moreau, P.; Massiani, M.-A.; Bouyer, A.-S.; Vuagnat, P.; et al. Characteristics and outcome of SARS-CoV-2 infection in cancer patients. JNCI Cancer Spectr. 2021, 5. [CrossRef]

42. Pullano, G.; Di Domenico, L.; Sabbatini, C.E.; Valdano, E.; Turbelin, C.; Debin, M.; Guerrisi, C.; Kengne-Kuetche, C.; Souty, C.; Hanslik, T.; et al. Underdetection of COVID-19 cases in france threatens epidemic control. Nature 2020, 1-9. [CrossRef]

43. Carrat, F.; Touvier, M.; Severi, G.; Meyer, L.; Jusot, F.; Lapidus, N.; Rahib, D.; Lydié, N.; Charles, M.-A.; Ancel, P.-Y.; et al. Incidence and risk factors of COVID-19-like symptoms in the french general population during the lockdown period: A multi-cohort study. BMC Infect. Dis. 2021, 21, 169. [CrossRef]

44. Kluytmans-van den Bergh, M.F.Q.; Buiting, A.G.M.; Pas, S.D.; Bentvelsen, R.G.; van den Bijllaardt, W.; van Oudheusden, A.J.G.; van Rijen, M.M.L.; Verweij, J.J.; Koopmans, M.P.G.; Kluytmans, J.A.J.W. Prevalence and clinical presentation of health care workers with symptoms of Coronavirus disease 2019 in 2 dutch hospitals during an early phase of the pandemic. JAMA Netw. Open 2020, 3, e209673. [CrossRef]

45. Delfraissy, J.F.; Atlani Duault, L.; Benamouzig, D.; Bouadma, L.; Cauchemez, S.; Chauvin, F.; Druais, P.L.; Fontanet, A.; Grard, M.A.; Hoang, A.; et al. Avis Du Conseil Scientifique COVID-19; 2020. Available online: https://www.vie-publique.fr/sites/ default/files/rapport/pdf/avis_conseil_scientifique_12_mars_2020.pdf (accessed on 15 June 2021).

46. Oved, K.; Olmer, L.; Shemer-Avni, Y.; Wolf, T.; Supino-Rosin, L.; Prajgrod, G.; Shenhar, Y.; Payorsky, I.; Cohen, Y.; Kohn, Y.; et al. Multi-center nationwide comparison of seven serology assays reveals a SARS-CoV-2 Non-responding seronegative subpopulation. EClinicalMedicine 2020, 29-30, 100651. [CrossRef]

47. Ong, D.S.Y.; Fragkou, P.C.; Schweitzer, V.A.; Chemaly, R.F.; Moschopoulos, C.D.; Skevaki, C. How to interpret and use COVID-19 serology and immunology tests. Clin. Microbiol. Infect. 2021. [CrossRef]

48. Jiang, C.; Wang, Y.; Hu, M.; Wen, L.; Wen, C.; Wang, Y.; Zhu, W.; Tai, S.; Jiang, Z.; Xiao, K.; et al. Antibody seroconversion in asymptomatic and symptomatic patients infected with severe acute respiratory syndrome Coronavirus 2 (SARS-CoV-2). Clin. Translat. Immunol. 2020, 9, e1182. [CrossRef]

49. Long, Q.-X.; Tang, X.-J.; Shi, Q.-L.; Li, Q.; Deng, H.-J.; Yuan, J.; Hu, J.-L.; Xu, W.; Zhang, Y.; Lv, F.-J.; et al. Clinical and Immunological assessment of asymptomatic SARS-CoV-2 infections. Nat. Med. 2020, 26, 1200-1204. [CrossRef]

50. Bastos, M.L.; Tavaziva, G.; Abidi, S.K.; Campbell, J.R.; Haraoui, L.-P.; Johnston, J.C.; Lan, Z.; Law, S.; MacLean, E.; Trajman, A.; et al. Diagnostic Accuracy of serological tests for Covid-19: Systematic review and meta-analysis. BMJ 2020, $370, \mathrm{~m} 2516$. [CrossRef]

51. Mekonnen, D.; Mengist, H.M.; Derbie, A.; Nibret, E.; Munshea, A.; He, H.; Li, B.; Jin, T. Diagnostic accuracy of serological tests and kinetics of severe acute respiratory syndrome Coronavirus 2 antibody: A systematic review and meta-analysis. Rev. Med. Virol. 2021, 31, e2181. [CrossRef] [PubMed]

52. Lee, C.Y.-P.; Lin, R.T.P.; Renia, L.; Ng, L.F.P. Serological approaches for COVID-19: Epidemiologic perspective on surveillance and control. Front. Immunol. 2020, 11. [CrossRef]

53. Doust, J.A.; Bell, K.J.L.; Leeflang, M.M.G.; Dinnes, J.; Lord, S.J.; Mallett, S.; van de Wijgert, J.H.H.M.; Sandberg, S.; Adeli, K.; Deeks, J.J.; et al. Guidance for the design and reporting of studies evaluating the clinical performance of tests for present or past SARS-CoV-2 infection. BMJ 2021, 372, n568. [CrossRef] 